Received: 19/07/2018

Revision: 13/10/2018

Accepted: $17 / 10 / 2018$

OnlineFirst: $31 / 10 / 2018$

\title{
A Comparison between Deductive and Inductive Approaches for Teaching EFL Grammar to High School Students
}

Carmen Benitez-Correa

Prof., Universidad Técnica Particular de Loja, Loja, Ecuador, cdbenitez@utpl.edu.ec

Paul Gonzalez-Torres

Prof., Universidad Técnica Particular de Loja, Loja, Ecuador, pfgonzalez@utpl.edu.ec

Cesar Ochoa-Cueva

Prof., Universidad Técnica Particular de Loja, Loja, Ecuador, caochoa@utpl.edu.ec

Alba Vargas-Saritama

Prof., Universidad Técnica Particular de Loja, Loja, Ecuador, abvargas@utpl.edu.ec

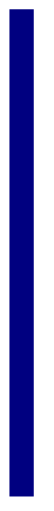

This study had the purpose of testing two methods for teaching grammar in English as a Foreign Language (EFL) class: the deductive and inductive approaches in terms of effectiveness and rapport. This research was conducted in a public high school in Ecuador. Seventy students enrolled in the second year of senior high school participated. One in-service teacher taught the EFL classes during the process of intervention (10 weeks), and two EFL teachers observed all of these classes and recorded the information by filling in observation sheets. The students were administered grammar pre-tests and post-tests in order to assess their grammar knowledge. The results of the tests showed a significant difference in the scores in favor of the inductive approach. After the statistical analysis of the data obtained from the tests and observation sheets, we concluded that the inductive approach is more effective for teaching grammar in the EFL classroom in terms of instruction and rapport.

Keywords: inductive approach, deductive approach, EFL teaching, rapport, teaching grammar

\section{INTRODUCTION}

Teaching grammar in an English as a Foreign Language (EFL) class plays an important role, mainly in terms of enabling students to achieve linguistic competence (Huang, 2005). Thus, finding a suitable method to teach it has been a subject of debate (R. Ellis, 2006; Thornbury, 1999). One of the most controversial and unanswered questions regarding effective language learning is the issue of whether grammar is taught

Citation: Benitez-Correa, C., Gonzalez-Torres, P., Ochoa-Cueva, C., \& Vargas-Saritama, A. (2019). A Comparison between Deductive and Inductive Approaches for Teaching EFL Grammar to High School Students. International Journal of Instruction, $12(1)$, 225-236. https://doi.org/10.29333/iji.2019.12115a 
deductively or inductively. This implies that the debate has always focused on how grammar could be taught explicitly, through a formal presentation of grammatical rules, or implicitly, through natural exposure to meaningful language use (Nassaji \& Fortos, 2011).

In this regard, Larsen-Freeman (2015) investigated whether students learn language rules best by giving them information deductively or by reading textbooks, or if students are better off being given examples from which they find out the rules inductively by themselves. One learning approach would favor induction, with the added benefit that students learn how to figure out the rules on their own. She also states that repeated examples could lead students to induce a rule, but it is also possible that language patterns are stored in learner's brain and may arise when they need to use the language. Therefore, the suggestion when teaching grammar deductively is to give students reasons as opposed to presenting rules, which may seem arbitrary, but they allow learners to see why things are the way they are; thus, reducing the opportunity of grammar explanations (Larsen-Freeman, 2000).

Another important issue that contributes to learning in the English classroom is rapport. Good rapport between students and teachers would be beneficial to raise students' motivation and interest in the classroom (Bouras \& Keskes, 2014). Since grammar is a controversial and difficult aspect of EFL teaching, it is important to maintain appropriate rapport in the EFL classroom when grammar is explained and practiced. Rapport is essential in establishing a relationship between teachers and students and maintaining it in order to work and learn well together. This relationship allows them to enjoy one another and the class so that students feel motivated to do their best (Paterson, 2005).

The purpose of this study was to try both approaches (inductive and deductive) to teaching grammar in order to determine which one is more effective in the EFL classroom. In this regard, despite the fact that Ecuadorian educators and authorities are aware of the importance of learning English and have adopted several measures to improve this process, students in Ecuador do not obtain the desired EFL proficiency level (El Comercio, 2017).

Therefore, the present study focuses on exploring the difference in effectiveness between the inductive and deductive approaches to teach grammar in the EFL classroom. Additionally, the effectiveness of rapport during the English lessons was also assessed. The research questions to be answered were the following:

1) Which of the two approaches is more effective for teaching EFL grammar?

2) How effective is rapport when teaching EFL grammar deductively and inductively?

\section{LITERATURE REVIEW}

\section{Teaching grammar inductively and deductively}

In the context of language teaching, grammar is a key component of language. Huang (2005) states that the main goal of teaching grammar is to enable learners to achieve 
linguistic competence to use grammar as a tool or resource for understanding and producing efficient, effective and proper oral and written discourse.

Teaching EFL grammar has been considered a controversial area of language teaching and learning (Negahdaripour \& Amirghassemi, 2016; Petraki \& Hill, 2010). This debate has been centered on issues such as the way grammar has been taught, its communicative purposes, whether to teach grammar at all, what sort of grammar to teach, the effectiveness of explicit or implicit grammar, or whether to teach it in context or not, whether it is advisable to teach it based on rules or examples, whether to teaching it descriptively or prescriptively, etc. (E. Ellis, 2006; Thornbury, 1999).

However, Thornbury (1999) highlights three main approaches to teaching grammar: teaching grammar based on rules, examples and through texts. Teaching grammar from rules involves the deductive or rule-driven approach, which starts with the introduction of a rule followed by examples in which the rule is applied. Teaching grammar from examples is related to the inductive or rule-discovery approach that starts with some examples from which a rule is inferred. Teaching grammar through texts is based on the principle that language is context-sensitive, that is, the intended meaning of a word or phrase is very difficult to determine without a context. In this approach, learners need to be exposed to the context by using texts in order to understand the grammar learned. One of the problems when using texts is that beginners or elementary learners might find it difficult to understand grammar in a natural context. In addition, taking words, sentences and texts out of contexts threatens their intelligibility.

Due to the weaknesses of teaching grammar through texts to beginners or elementary learners, this study emphasizes the use of deductive and inductive approaches to teach grammar to EFL students in high school, particularly, young adult beginners.

Deductive teaching is a traditional method in which information about the target language and rules is given at the beginning of a class and complemented with examples. The principles of this approach are generally used in classes where the main target is to teach grammar structures. For instance, these principles are convenient for classes in which grammar translation method is applied (Nunan, 1991; Shrum \& Glisan, 2016). In addition, In a deductive lesson the teacher should first present the grammar rules. Then examples highlighting the grammar structures should be provided by the teacher. Lastly, students use the rules in order to produce their own examples. In fact, the expected outcome of a deductive approach sees the need to teach grammar in an explicit way to help learners to be aware of the grammar rules (Thornbury, 1999; Shrum \& Glisan, 2016).

On the other hand, there is a belief that, in an inductive method, learners analyze examples in a context (e.g. text or audios) to discover the grammar rules by themselves. At the end of this process, after students have discovered the grammar patterns, they create their own examples; thus practicing the language (Nunan, 1999; Thornbury, 1999; Shrum \& Glisan, 2016).

Teaching grammar to EFL learners after the critical period has some important pedagogical implications, since, as Brown (2007) explains, the adult mentality of 
thinking about abstract items allows them to cope with rules when they are exposed to the target language. In addition, he posits that the deductive approach is more suitable for adult learners. Deductive teaching meets these learners' expectations because, for them, the presentation of grammar rules at the beginning of the lesson is really useful when learning a language. Conversely, young students are better at learning grammar structures from examples rather than learning them deductively; they prefer to learn by practicing because grammar rules are complicated for them to understand.

\section{Rapport in the EFL classroom}

There are three motivational conditions that are important at the moment of teaching: appropriate teacher behaviors and a good relationship with the students; a pleasant and supportive classroom atmosphere, and a cohesive learner group with appropriate group norms (Dörnyei, 2001). Since motivation is important in the teaching-learning process, it is essential to establish good communication between teacher and students to achieve a successful and positive teaching and learning process (Barmaki, 2014). This enjoyable and respectful relationship of communication is called rapport, which involves a balanced interaction and trust between teacher and students (Harmer, 2007).

According to Dörnyei (2001), EFL teachers can implement strategies in the classroom for building rapport such as greeting students, remembering their names, noticing interesting features of their appearance, learning something unique about each student, asking them about their lives outside school, showing interest in their hobbies, recognizing birthdays, moving around in class, including personal topics and examples, and assign homework to absent students.

Proper rapport between the teacher and students involves harmonious understanding of each other as individuals, based on mutual respect and esteem. On the other hand, inappropriate behavior by teachers, which indicates that they have little respect or esteem for students, will inevitably undermine the development of good rapport. In other words, rapport is one of the teacher's skill for a "sound relationship between a teacher and pupils" (Kyriacou, 2009, p. 109).

\section{Previous studies}

Previous research has studied the effects of using inductive and deductive approaches and the interaction between these approaches for teaching the active and passive voice in an EFL context. The results indicate significant differences in favor of the deductive group, but no significant differences were found between the groups that received the same type of approach (Mohammed \& Jaber, 2008).

When it comes to the effects of the deductive and inductive techniques of grammar instruction on EFL learners' accuracy and fluency, Negahdaripour and Amirghassemi (2016) conducted a quasi-experimental study that attempted to compare the performances related to the fluent and accurate use of English tenses of two groups of Iranian EFL students: the deductive and the inductive instruction group. No significant differences were found between the groups in terms of their oral fluency. However, there was a significant difference with respect to their accurate use of two of the English 
tenses. This means that the deductive approach towards grammar had a more positive effect on EFL learners' oral accuracy.

The effects of indirect explicit grammar instruction on EFL learners' use of English tenses have also been examined. The experimental group, who learned grammar through the indirect approach, significantly outperformed the control group, who worked with the direct approach, as to the analysis of grammar rules and the oral proficiency, except for the use of grammar structures in a pre-defined context. Therefore, the findings indicated favorable results for indirect explicit grammar instruction. There was also a positive correlation between the grammar rules and their use (Dang \& Nguyen, 2012).

Studies have also been aimed at exploring English teachers' and students' beliefs about teaching grammar. In this respect, the findings of Deng and Lin (2016) reveal the teachers' perception that language teaching should be more focused on meaning and less focused on form. When comparing the deductive and inductive approaches to teaching English grammar, the majority of teachers prefer the deductive method. As for the students' grammar beliefs, they have positive views of the communicative and traditional grammar focus.

Other studies that have attempted to find differences between inductive and deductive strategies in teaching grammar have found no evidence of significant differences when using an inductive or a deductive strategy for teaching grammar (Zamani \& Mohammadi, 2014).

The aforementioned studies reveal that there is not an agreement on which approach is more effective to teach grammar in an EFL context. The debate is still open in this respect but, if the purpose is to teach grammar using communicative methods, instructors would tend to teach grammar inductively.

\section{METHOD}

\section{Setting and participants}

This study was conducted in a public school in Ecuador where students regularly attend 5 EFL classes per week (45 minutes each class). Two classes (seventy students), which were randomly chosen from seven available classes that belonged to the second year of senior high school, participated in this study. Their ages ranged from 15 to 17 years old, and their English proficiency level varied between A1 and A2 according to the Common European Framework of Reference (CEFR). One EFL teacher imparted the lessons during this intervention, and two EFL teachers participated as observers.

\section{Instruments}

The instruments used included an observation sheet, and a pre-test and post-test. The observation sheet was piloted with the help of 10 EFL teachers in order to assure that the items are aligned with the purpose and design of the present study. On the other hand, the pre and post-test were previously piloted on 20 high-school students so we can detect possible errors in the comprehension of the questions and estimate the time needed to complete the test. 
The observation sheet, which contained seven items, was used to record information on different aspects related to rapport such as feelings, enthusiasm, interest, feedback, interaction, and confidence in the EFL class. The pre-test and post-test (each one was graded out of 10 points), which consisted of 25 multiple-choice questions each, were administered to assess the students' knowledge related to EFL grammar in terms of structures such as simple present and simple past tenses, future with will and be going to, Wh-questions, present perfect and comparatives and superlatives. We established a qualitative scale for the scores obtained in both pre and post-test for reference purposes (1-2: poor; 2.1-4: fair; 4.1 - 6: good; 6.1-8: very good; 8.1-10: excellent).

\section{Procedure}

Due to the fact that we worked with two classes, each class was assigned to a group: experimental and control group. This means that our study has a quasi-experimental nature since the participants for the two groups were not randomly selected (Creswell, 2015).

Before starting the intervention, the students took an EFL grammar pre-test in order to know their initial grammar knowledge of the structures to be studied. The two groups experienced different grammar teaching approaches. One group (36 students) received EFL classes in which the inductive grammar approach was used. The second group (34 students) were taught by means of the deductive grammar approach. The lessons were imparted for a period of 10 weeks and each group received a total number of 15 hours of instruction (1.5 hours per week).

In the deductive approach group, grammatical points were explained in class and students were allowed to ask questions; moreover, direct feedback was provided for learners by underlining the errors referring to the grammatical rules. The activities for teaching grammar in this group included completing handouts, writing sentences on the board in order to explain grammar patterns, reading and writing passages, and having students do exercises using the grammar structures taught.

For example, in the deductive group, one of the contents studied was related to the use of "will" for expressing future in affirmative sentences. The class started by presenting a sentence using this structure on the board. The teacher then asked the students to identify the parts of the sentence such as subject, verb and complement, and the modal auxiliary "will". The teacher explained that "will" goes before the verb and gives the tense (future) to the sentence. It was also explained that when we use the modal auxiliary "will", the verb is used in the base form. To complete the explanation, the teacher reminded the students that future sentences that use "will" follow the pattern subject + modal auxiliary + base form of the verb + complement. Later on, the students practiced the use of the structure through substitution drill exercises through which they internalized the use of the modal auxiliary "will" with different subjects and verbs.

The inductive approach group was exposed to implicit instruction of grammar. The students worked in activities, which involved them in an unconscious learning of grammar with the focus on message over abstract form. Those activities comprised watching short videos about live sports, interviews, listening to and analyzing songs, 
performing role plays, describing pictures, completing cloze exercises, substitution drills and writing creative texts. The students under the inductive teaching condition received feedback in context through recasting rather than providing direct feedback.

For example, in the inductive group, the teacher brought some fruits to the class and asked the students questions such as "What do you see here?" Students responded by using phrases such as "an apple", " a pear", "an orange", etc. The teacher wrote sentences such as "there is an apple", "there is a pear", etc. The teacher made sure that students notice (by underlining) that "there is" is used to express the existence of a single object. Then, the teacher showed sets of two or more fruits (e.g. two apples, three oranges, three pears) and elicited more responses from the students. Students answered using sentences such as "apples" or "two apples". Likewise, the teacher wrote sentences such as "There are two apples/oranges/pears" and made clear (by underlining the structure) for the students the use of are with the plural form. Finally, the teacher handed students some flashcards containing either one or more than one object (e.g. cars, toys, fruits, etc.) and asked students to write sentences using "there is" or "there are" according to the picture. The teacher provided indirect feedback so that students could notice the use of "there is" or "there are" by associating the singular or plural form with the use of the verb " to be".

In this respect, according to Richards and Schmidt (2010) language teaching methods that use the deductive approach emphasize the study of the grammatical rules of a language (e.g. the grammar translation method). In contrast, language teaching methods that apply inductive learning focus on the use not on presentation of the language (e.g. the direct method, communicative approach, and counselling learning).

After the intervention, students in both groups were administered a grammar post-test with the purpose of monitoring their progress in learning EFL grammar by means of the two aforementioned approaches. The pre-tests and post-tests were graded and the scores obtained were compared in both the experimental and control groups by means of statistical procedures; in this case, t-test by using a confidence level of $95 \%$.

During the intervention, the two EFL teachers observed the development of the lessons to determine the effectiveness of rapport in class by filling in observation sheets. Thus, in order to analyze the level of efficiency related to rapport in both groups, the results were analyzed by counting the frequencies and determining the percentages and modes.

\section{FINDINGS}

As was mentioned, the pre and post-tests were graded out of 10 points each. The average of the scores obtained by the two groups are shown in tables 1 and 2 (mean).

First of all, we could determine that the scores of the pre-tests and post-tests in both groups indicated a normal distribution. For this reason, the the t-test was used to compare the averages of the two groups (independent samples) and the two types of tests (paired samples) in order to find significant differences (Urdan, 2011).

After applying the t-test, the following tables and values were obtained in order to find out which approach (inductive or deductive) to teaching grammar was more effective. 
In the group of students who attended classes with the deductive method (see Table 1), it can be seen that there is a significant increase in the scores between the grammar pretest and the post-test $(\mathrm{t}=8.2395 ; \mathrm{p}<0.0001)$. This increase between the scores of the pre-test and post-test is also significant in the group (see Table 2) who received classes with the inductive method $(\mathrm{t}=10.0901 ; \mathrm{p}<0.0001)$. This means that if we apply the qualitative scale established for the test (see the section "Instruments" above), the deductive group went from "fair" to "good", while the inductive groups went from "fair" to "very good", which provides further support for the use of the inductive approach.

Table 1

Deductive approach group

\begin{tabular}{lll}
\hline Statistic & Pre-test & Post-test \\
\hline Mean & 3.518 & 5.753 \\
\hline SD & 0.660 & 0.961 \\
\hline
\end{tabular}

$\mathrm{t}=8.2395$

$\mathrm{p}<0.0001$

Table 2

Inductive approach group

\begin{tabular}{lll}
\hline Statistic & Pre-test & Post-test \\
\hline Mean & 3.667 & 6.506 \\
\hline SD & 0.689 & 1.057 \\
\hline
\end{tabular}

$\mathrm{t}=10.0901$

$\mathrm{p}<0.0001$

With respect to the pre-test, the difference in scores between the deductive and inductive group was not significant $(\mathrm{t}=0.6526 ; \mathrm{p}=0.5185)$ before the intervention; thus, both groups had a similar level of grammar knowledge. After the intervention a significant difference in the post-test was observed $(\mathrm{t}=2.1998 ; \mathrm{p}=0.0349)$ (see Table 3 ).

Table 3

Results of the post-test in the deductive and inductive

\begin{tabular}{lll}
\hline Statistic & Deductive & Inductive \\
\hline Mean & 5.753 & 6.506 \\
\hline $\mathrm{SD}$ & 0.961 & 1.057 \\
\hline $\mathrm{t}=2.1998$ & & \\
$\mathrm{p}=0.0349$ & &
\end{tabular}


Concerning rapport, in general, the results obtained from the observation sheets indicated that rapport in the deductive approach (see Table 4) were effective (MODE = 2 ). In the first item, it can be seen that, in most classes (10 out of 15 classes) students were interested in the class. The results also show that the teacher was respectful and impartial in most of the classes (13 out of 15 classes). Concerning feedback, it was provided in more than half of the classes (9 classes).

In all of the classes, students were encouraged to participate, and in most of them, they interacted with the teacher and showed enthusiasm as well (10 classes). Students also felt confident when asking for further explanation (12 classes).

Table 4

Rapport in the deductive approach

\begin{tabular}{|c|c|c|c|c|c|c|}
\hline Aspects of rapport & $\begin{array}{l}\text { Slightly } \\
\text { effective }\end{array}$ & $\%$ & Effective & $\%$ & $\begin{array}{l}\text { Highly } \\
\text { effective }\end{array}$ & $\%$ \\
\hline 1. Students are interested in the class & 5 & $33.33 \%$ & 7 & $46.67 \%$ & 3 & $20 \%$ \\
\hline 2. Teacher is respectful, fair and impartial & 2 & $13.33 \%$ & 9 & $60 \%$ & 4 & $26.66 \%$ \\
\hline 3. Teacher provides feedback & 6 & $40 \%$ & 7 & $46.67 \%$ & 2 & $13.33 \%$ \\
\hline 4. Students are encouraged to participate in class & 0 & $0 \%$ & 11 & $73.33 \%$ & 4 & $26.66 \%$ \\
\hline 5. Students interact with teacher & 5 & $33.33 \%$ & 6 & $40 \%$ & 4 & $26.66 \%$ \\
\hline 6. Students show enthusiasm & 5 & $33.33 \%$ & 8 & $53.33 \%$ & 2 & $13.33 \%$ \\
\hline $\begin{array}{l}\text { 7. Students feel confident when asking for further } \\
\text { explanations }\end{array}$ & 3 & $20 \%$ & 9 & $60 \%$ & 3 & $20 \%$ \\
\hline
\end{tabular}

As for the classes in which the inductive method was used (see Table 5), rapport was also effective (MODE $=2$ ). In the majority of classes, the results evidence that students showed interest (12 out of 15 classes), the teacher was respectful (14 classes) and feedback was provided (13 classes). Additionally, in most of the classes, students were encouraged to participate (14 classes), interacted with the teacher (12 classes), showed enthusiasm (12 classes), and felt confident when asking for explanations (13 classes).

Table 5

Rapport in the inductive approach

\begin{tabular}{llllllll}
\hline Aspects of rapport & $\begin{array}{c}\text { Slightly } \\
\text { effective }\end{array}$ & $\%$ & Effective & $\%$ & $\begin{array}{l}\text { Highly } \\
\text { effective }\end{array}$ & $\%$ \\
\hline 1. & Students are interested in the class & 3 & $20 \%$ & 8 & $53.33 \%$ & 4 & $26.66 \%$ \\
\hline 2. & Teacher is respectful, fair and impartial & 1 & $6.67 \%$ & 11 & $73.33 \%$ & 3 & $20 \%$ \\
\hline 3. & Teacher provides feedback & 2 & $13.33 \%$ & 7 & $46.67 \%$ & 6 & $40 \%$ \\
\hline 4. & Students are encouraged to participate in class & 1 & $6.67 \%$ & 11 & $73.33 \%$ & 3 & $20 \%$ \\
\hline 5. & Students interact with teacher & 3 & $20 \%$ & 8 & $53.33 \%$ & 4 & $26.66 \%$ \\
\hline 6. & Students show enthusiasm & 3 & $20 \%$ & 9 & $60 \%$ & 3 & $20 \%$ \\
\hline 7. & Students feel confident when asking for explanations & 2 & $13.33 \%$ & 12 & $80 \%$ & 1 & $6.67 \%$ \\
\hline
\end{tabular}


To sum up, it can be observed that, although both approaches to teaching grammar have been effective in terms of rapport, the percentages of effectiveness in rapport in the inductive group are slightly higher.

\section{DISCUSSION}

First of all, it is important to mention that the grammar knowledge of both groups, deductive and inductive, were similar at the beginning of the intervention as evidenced in the results of the pre-tests. This similarity makes the two groups comparable. At the end of the intervention, the significant increase in the scores in the post-test show that both groups improved their grammar knowledge after taking EFL grammar lessons with the deductive and inductive approaches.

When comparing both approaches, the significant difference in the scores of the groups indicate that the inductive approach was more effective than the deductive approach when teaching grammar to these students (see Table 3). These findings are consistent with studies such as the one by Dang and Nguyen (2012), which favors an indirect approach over a direct one for teaching grammar rules. However, other studies have given an advantage to the deductive method (e.g. Mohammed \& Jaber, 2008; Deng \& Lin, 2016; Negahdaripour \& Amirghassemi, 2016) and others have found no significant difference when using the two approaches in teaching grammar (e.g. Zamani \& Mohammadi, 2014).

In addition, the results obtained from the observations mean that rapport was more effective in the inductive group rather than in the deductive one, which might be caused by a more dynamic teaching process involved in the communicative approach activities that were used as a part of the inductive method for teaching grammar.

\section{CONCLUSION}

The present study explored the difference in effectiveness between the inductive and deductive approaches as well as the effectiveness of rapport when teaching grammar in an EFL context. After the analysis and discussion of results, the following conclusions have been drawn:

Both groups had a similar level of grammar knowledge before the intervention, which improved after it; however, the statistical analysis shows that the inductive approach had a slight advantage in terms of improving students' grammar knowledge.

There was an effective rapport in the EFL classes in both groups. However, the rapport observed in the inductive approach group was slightly more effective, considering aspects such as the teacher being respectful, feedback being provided, students participating in class and interacting with teachers, enthusiasm, and confidence when asking for explanations in class.

Despite the fact that the present study favors the inductive approach as a more effective method to teaching EFL grammar, we have to consider the fact that this is a study conducted in one high school and may not be generalizable to other contexts. It is suggested to continue doing research on this controversial issue in different EFL 
contexts with larger samples and longer intervention periods. These studies can be done especially in Latin American countries, where this aspect has not been deeply explored.

\section{REFERENCES}

Barmaki, R. (2014). Nonverbal communication and teaching performance. Proceedings of the 7th International Conference on Educational Data Mining (EDM), 441-443. Retrieved from http://educationaldatamining.org/EDM2014/uploads/procs2014/YRT/441_EDM-2 014Full-Proceedings.pdf.

Bouras, H., \& Keskes, S. (2014). Teacher-learner rapport impact on EFL learners' motivation. In International Conference on Social Sciences and Humanities. Istanbul, Turkey. Retrieved from www. Ocerint org/Socioint14_ebook/papers/201. pdf.

Brown, H. D. (2007). Teaching by principles: An interactive approach to language pedagogy. Englewood Cliffs: Prentice Hall Regents.

Creswell, J., W. (2015). Educational research: planning, conducting and evaluating quantitative and qualitative research. Harlow, Essex: Pearson Education Limited.

Dang, T. T. D., \& Nguyen, H. T. (2012). Direct Versus Indirect Explicit Methods of Enhancing EFL Students' English Grammatical Competence: A concept CheckingBased Consciousness-Raising Tasks Model. English Language Teaching, 6(1), 112121.

Deng, F., \& Lin, Y. (2016). A Comparative Study on Beliefs of Grammar Teaching between High School English Teachers and Students in China. English Language Teaching, 9(8), 1-10.

Dörnyei, Z. (2001). Motivational strategies in the language classroom. Cambridge: Cambridge University Press.

El Comercio (2017, November, 10). El nivel de inglés en el Ecuador todavía es bajo. Retrieved May 15, 2018 from www.elcomercio.com/tendencias/ecuador-nivel-inglesadultos-educacion.html

Ellis, E. M. (2006). Language Learning Experience as a Contributor to ESOL Teacher Cognition. TESL-EJ, 10(1), 1-7.

Ellis, R. (2006). Current Issues in the Teaching Grammar: An SLA perspective. TESOL Quarterly, 40(1), 83-107.

Harmer, J. (2007). How to teach English. New York: Pearson Education Limited.

Huang, Z. (2005). Grammar Teaching as Product or as Process? Sino-US English Teaching, 2(11), 27-31.

Kyriacou, C. (2009). Effective teaching in schools: Theory and practice. Cheltenham: Nelson Thornes. 
Larsen-Freeman, D. (2000). Grammar: Rules and Reasons Working Together. ESL/EFL Magazine, 3(1), 10-12.

Larsen-Freeman, D. (2015). Research into Practice: Grammar Learning and Teaching. Language Teaching, 48(2), 263-280.

Mohammed, A. A., \& Jaber, H. A. (2008). The Effects of Deductive and Inductive Approaches of Teaching on Jordanian University Students' Use of the Active and Passive Voice in English. College Student Journal, 42(2), 545-553.

Nassaji, H. \& Fortos, S. (2011). Teaching grammar in second language classroom: Integrating form-focused instruction in communicative context. New York: Routledge.

Negahdaripour, S., \& Amirghassemi, A. (2016). The effect of deductive vs. inductive grammar instruction on Iranian EFL Learners' Spoken Accuracy and Fluency. International Journal of Applied Linguistics and English Literature, 5(1), 8-17. http://dx.doi.org/10.7575/aiac.ijalel.v.5n.1p.8

Nunan, D. (1991). Language teaching methodology: A textbook for teachers. London: Prentice Hall International LTD.

Nunan, D. (1999). Second language teaching \& learning. Boston: Heinle \& Heinle Publishers.

Paterson, K. (2005). 55 Teaching dilemmas: Ten powerful solutions to almost any classroom challenge. Ontario: Pembroke Publishers.

Petraki, E., \& Hill, D. (2010). Theories of Grammar and Their Influence on Teaching Practice: Examining language teachers' beliefs. University of Sydney Papers in TESOL, 5(5), 65-99.

Richards, J. C. \& Renandya, W. (2002). Methodology in language teaching: An anthology of current practice. New York: Cambridge University Press.

Richards, J. C., \& Rodgers, T. S. (2014). Approaches and methods in language teaching. Cambridge: Cambridge university press.

Richards, J. C., \& Schmidt, R. (2010). Longman dictionary of language teaching and applied linguistics (4th ed.). London: Longman Pearson Education.

Shrum, J. L. \& Glisan E. W. (2016). Teacher's handbook contextualized language instruction. Boston: Cengage Learning.

Thornbury, S. (1999). How to teach grammar. Harlow, Essex: Longman.

Urdan, T. C. (2011). Statistics in plain English. New York: Routledge.

Zamani, A., \& Mohammadi, F. A. (2014). A Comparison between Using an Inductive Strategy and a Deductive one in Grammar Instruction for Iranian EFL Learners. Enjoy Teaching Journal, 2(1), 90- 98. 